
\title{
R Research Soure \\ Research on Inequality of Household Consumption and Social Welfare from the Perspective of Household Non-medical Expenditure
}

Tiantian Hu

Wuhan University

Huan Liu ( $\square$ zcliuhuan@126.com )

Zhejiang Unversity of Finance \& Economics https://orcid.org/0000-0001-8772-1545

\section{Research}

Keywords: household consumption, inequality, social welfare, economic growth, consumption distribution

Posted Date: March 11th, 2020

DOI: https://doi.org/10.21203/rs.3.rs-16944/v1

License: (c) (i) This work is licensed under a Creative Commons Attribution 4.0 International License.

Read Full License 


\section{Title Page}

Manuscript Type: Original Research

Title of Manuscript:

Research on Inequality of Household Consumption and Social Welfare from the Perspective of Household Non-medical Expenditure

\section{Authors' name and affiliation:}

1. Name of First Author:Tiantian Hu, Ph.D.

Affiliation: Center for Social Security Studies, Wuhan University, Wuhan,China

Email:krebecca@yeah.net

2. Name of Second Author:Huan Liu, Ph.D.

Affiliation: School of Public Administration, Zhejiang University of Finance \& Economics,Hang Zhou, China

Email:zcliuhuan@126.com

\section{Name of Corresponding author Author *: Huan Liu}

Affiliation: School of Public Administration, Zhejiang University of Finance \& Economics,Hang Zhou,China

Email:zcliuhuan@126.com

Tel: +8618042418732

Address:School of Public Administration, Zhejiang University of Finance \& Economics, No. 18 Xueyuan Street, Xiasha Higher Education Park, 310018, Hangzhou, Zhejiang, China

\section{Declarations}

Ethics approval and consent to participate

Not applicable

Consent for publication 
Not applicable.

Availability of data and materials

The original data of the article comes from: https://www.cpc.unc.edu/projects/china/

\section{Competing interests}

The authors declare that they have no competing interests.

\section{Funding}

Funding:National Natural Science Fund of China ( 71904167 ) and Zhejiang Philosophy and Social Science Planning Project (20NDQN302YB)

\section{Authors' contributions}

Huan Liu made a substantial contribution to the concept and design of the work, interpretation of data,and drafted the article.Tiantian $\mathrm{Hu}$ revised it critically for important intellectual content and approved the version to be published.

\section{Acknowledgements}

The authors are very grateful for the financial support of National Natural Science Fund of China (71904167) and Zhejiang Philosophy and Social Science Planning Project (20NDQN302YB). 


\section{Research on Inequality of Household Consumption and Social}

\section{Welfare from the Perspective of Household Non-medical Expenditure}

\section{Abstract}

\section{Background}

In China, income inequality has raised substantially over the last 40 years, especially after $21 \mathrm{st}$ century. The rise in inequality in China has received considerable attention in academic field. But existing studies have paid more attention to comparative research on the relationship between household income inequality and consumption inequality, and ignored the impact of social welfare changes on household or overall consumption levels during the same period.

\section{Methods}

In this paper, we present an analysis of the trends in inequality of income and consumption in China from 1998 to 2015.Based on the data of China Health and Nutrition Survey(CHNS),we find that household income and consumption inequality have increased substantially over last 30 years.Utilize the inequality of consumption and social welfare and according to the differences in the composition of household consumption, medical consumption is used as the dividing standard to evaluate the inequality of non-medical consumption. In terms of empirical tests, a mixed-panel ols model was constructed to explore the inequality differences in household consumption under non-medical consumption and medical consumption samples. 


\section{Results}

First, in terms of consumption inequality, from 1989 to 2015, Chinese household income inequality and consumption inequality showed an increasing trend. Among them, overall consumption inequality was mainly caused by urban and rural consumption inequality. Second,the results show that in terms of overall social welfare, the deterioration of consumption distribution has replaced the growth of social welfare caused by economic growth, and the estimated results under non-medical consumption inequality are less different from the overall. Third, the results of the panel fixed-effect test show that income inequality is the main positive influence factor on consumption inequality, but participation in medical insurance has a negative impact on urban and rural household consumption inequality,illness has a negative impact on household medical inequality and non-medical consumer inequality.

\section{Conclusion}

The result can provide a solid reference for understanding China's consumption inequality and also political implications for the government to weigh efficiency and fairness.From the perspective of consumption policy interventions, it is necessary to promote government departments to better safeguard the health maintenance of healthy or sub-healthy people through health management policies, and promote the cost protection effect of basic medical insurance policies on unhealthy people.

Keywords:household consumption;inequality;social welfare; economic growth; consumption distribution

\section{Background}

In China, income inequality has raised substantially over the last 40 years, especially after21st century.The rise in inequality in China has received considerable attention in academic field. There is a large and growing literature that documents and analyzes the evolution of income, consumption and wealth inequality.Measuring the degree of inequality and analyzing the impact of inequality on the social welfare of residents is an important aspect of understanding inequality. Consumption inequality is a better measure of economic inequality. Since income inequality reflects people's inequality in the possession of social wealth,consumption inequality reflects people's inequality in access to social resources, thus consumption inequality is more harmful to the economy and society.

Existing research has focused on income or wealth inequality, and research on consumption inequality is rare:First, the Gini coefficient is the most important indicator for measuring inequality, and there is few measure of the Gini coefficient of Chinese consumption.Second, consumption can better reflect social welfare situation. Research on the impact of consumption 
distribution on social welfare is very rare.The main contribution of this research is reflected in these issues:On the one hand, using the micro-household income and expenditure group data, the Gini coefficient of Chinese household consumption is estimated, and the consumption Gini coefficient is decomposed according to the urban and rural groups.On the other hand, based on the estimated consumption Gini coefficient results, this paper analyzes the impact of consumption distribution on residents' social welfare.The estimation of the consumption Gini coefficient has significant meaning for cognition and narrowing consumption inequality. The social welfare analysis based on the consumption Gini coefficient has policy implications for balancing economic growth and controlling inequality.

In this paper we use a long panel data sources to document salient facts of the distribution of income, consumption and wealth in China. China's rapid economic growth in the last four decades has resulted in impressive income growth by its 'reform and opening up' and 'Urban-rural dual economic system'.At the same time, China has transformed from a relatively homogeneous society to one with great variation in the income,consumption, and wealth of its people.

\section{Literature review}

Compared to income inequality, consumption inequality has better traits, which can reflect more information and perform better measure of economic inequality. First, there is a higher proportion of invisible income in China. Income cannot fully reflect the living standards and welfare levels of residents. Consumption is a better indicator, especially for families with relatively poor resources. Second, according to the long-term income hypothesis of consumption and the life cycle hypothesis, residents are used to smoothing their lifetime consumption by their life income. The measure of income inequality generally refers to current income, rather than persistent income, which is highly volatile. Thus, consumption is less volatile and more measurable. Third, the income level does not reflect the accumulation of wealth, uncertainty, and the ability to obtain credit, and these factors can be reflected in consumption. Fourth, consumption can better reflect social welfare [1] . The most commonly used Cobb-Douglas utility function is measured by consumption, and the World Bank also defines the poor by consumption level.

A great deal of researches have been carried out in the context of China,e.g the internal inequality in China's rural area [2.3]; the evolution of rural-urban inequality[4,5]; and the inequality trends in urban area and determining factors behind the trend[ $[\underline{6}, 7, \underline{8}]$.Second,in terms of research in other countries,for example,over the entire period of 1997 to 2009,consumption inequality increased moderately in Canada [9,10]. Attanasio et al.[11],Blundell \& Etheridge [1]based on British, explored the path from income inequality to household consumption inequality, thus established a consistent link between microeconomics and macroeconomic analysis of the evolution of inequality.The existing research conclusions mainly focus on the following aspects:First, inequality in disposable income is found to be substantial,consumption inequality is less substantial[1ㄹ, $13, \underline{14}]$.Second, the increase in income inequality is related to an increase in the degree of earnings' instability rather than to shifts in the wage structure $[\underline{15}, \underline{16}]$.Third,the measures of consumption inequality are useful in addition to a chain as 
follows:Wages-Earnings-Income-Consumption-Material Well-being [푸, 18, $\underline{19}]$.

In the previous studies,most coclusions have analyzed the evolution of inequality based on empirical research data[20,21].Although there are a number of advantages in the design of these surveys, such as quite detailed information on income sources,covered selected provinces and so on.However, most research data is short-term,the representativeness of the survey sample and the inequality measurement method is biased. Previous studies on inequality have focused primarily on income inequality $[7, \underline{22}, \underline{23}]^{\oplus}$.Measuring consumption suffers less from under-reporting problems than measuring income since under-reporting of income has arguably been a serious challenge for all household surveys in China ${ }^{2}$.Moreover, in the existing research, the influence of social welfare factors is less involved, and welfare changes may be the key to regulating the inequality of household consumption. Thus, to better understand the changes in household welfare over the period 1989 2015 in China, we examine trends in consumption inequality. And empirically analyze the shortcomings of China's social welfare development under the change of consumption inequality. The main marginal contributions of the article are: 1) We have used long panel data to measure changes in consumption inequality in China from 1989 to 2015;2) We have decomposed consumption inequality and explored the core factors that cause consumption inequality; 3) We have introduced changes of the families' social welfare into the model and analyzed its impact on the coefficient of consumption inequality. We try to expand the research from the following points: 1) Systematic estimation from 1989 to 2015 of China's urban and rural overall consumption inequality evolution and social welfare changes; 2) Based on existing research, according to medical consumption classification, estimate non-medical consumption differences in coefficients under inequality, revealing the contribution of sickness and basic medical insurance to the current unequal consumption of Chinese households; 3) In the expansive test section, the empirical test of sickness and basic medical insurance on overall household consumption inequality is conducted through panel fixed effects impact mechanism.

\section{Methods}

\section{Measurement model of consumption inequality}

According to the analysis of Roemer[료, $\underline{29}]$, Ferreira \& Gignoux [30], etc., we first mark N discrete families as $i$, among them, $i \in\{1, \ldots . ., N\}$.Drawing on inequality, the article has set household consumption as a function of regional economic level,that is, if the household faces a set of environmental variables $H_{i}$, then there is $y_{i}=f\left(H_{i}, e_{i}\right)$.

According to above assumptions, the household can be classified three dimensions. The first is the household "advantage",expressed in $y$, representing the level of income earned by the household; the second is the "environment" dimension,expressed in $H$,representing a series of variables that do not change with the subjective will of the household but affect the equal opportunity of the household,we choose the urban and rural register, the education level of the

\footnotetext{
(1) However, current income may not accurately reflect resources available to families in the long run, and consumption expenditure is a more direct and precise measure of welfare and long-term earnings capacity than current income $[\underline{24}, \underline{25}, \underline{26}, \underline{27}]$.

(2) Because job-related benefits and "gray" income outside regular jobs are usually not reported.
} 
household, and the size of the household as the main environmental variables. The third is the average household's "effort",expressed in $e$, representing factors controlled by household individual factors.Among them, the average household effort level is regarded as a continuous variable, for each household, $\boldsymbol{H}_{i}$ is a vector of finite $J$ elements, and each element corresponds to it in a specific environment.Therefore, we assume that environmental variables are exogenous because families are not able to influence the environment.,however, environmental factors can affect the level of household efforts, so it is a one-way impact relationship.

Dividing whole sample of household as into a series of mutually exclusive "types" is an important way to measure opportunities of inequality.Assuming that there are a total of $M$ groups,we can mark these "types" as $\Pi=\left\{T_{1}, \ldots . ., T_{M}\right\}$.For any single group $m$, the population of this group faces similar environmental condition.For the difference in the level of effort between families, it is assumed that the relative effort level is distributed into [0,1].Set $\pi \in[0,1]$, the level of household effort of the $\pi$ quantile is $e^{m}(\pi)$, so when set the first group of families as $m$,the income level obtained by the household of the quantile can be defined as $u^{m}(\pi)=y^{m}\left[e^{m}(\pi)\right]$.According to the hypothesis above of household difference of $\mathrm{M}$ group, $u=\left(u^{1}, \ldots \ldots, u^{M}\right)$, using $u^{m}$ to indicate the income level of the $m$ household, the N-dimensional smoothed distribution of household income levels is indicated by vector $u=\left\{u_{i}^{m}\right\}$.

In order to get of inequality value within and between groups, the paper uses the generalized entropy index method, which is the only measure meets the decomposition requirements within and between groups[31,32] (Bourguignon, 1979; Shorrocks, 1980).Here, the theil index of the generalized entropy index method is used to calculate the log-mean deviation, and the inequalities between groups and within groups are decomposed,the main formula is:

$$
\begin{gathered}
\text { Theil }_{1}=\sum_{i=1}^{M}\left(\frac{A_{m}}{A}\right) T_{m} \\
\text { Theil }_{2}=\sum_{i=1}^{M}\left(\frac{A_{m}}{A}\right) \ln \frac{A_{m} / A}{P_{m} / P}
\end{gathered}
$$

Where $\mathrm{M}$ is the number of groups and $A$ is the total number of families. $A_{m} / A$ represents the share of the number of families of the group $m$ in the total number of families $(A) ; P_{m} / P$ is the share of a group's consumption in total income; $T_{m}$ is the consumption theil index of the group $m$.The first term on the right side of formula (1) represents the theil index within the group, and the second term is the theil index between groups.For the purpose of this study, it is necessary to adjust the formula (1).We replaced the income level grouping criteria with the environmental characteristics grouping criteria to distinguish the groups further.In general, the smaller the theil index, the smaller the difference in environmental variables.If the income share is equal to the household share, the share ratio of the logarithm is 1 , the logarithm is 0 , and the theil index is also 0 , indicating that there is no difference between the environmental variables; if the share ratio is greater than 1 , the corresponding logarithm value will be greater than 0 ;if the share ratio is less than 1 , the corresponding logarithm value will be less than zero.When the share of consumption level is relatively smaller than the share of families numbers, the logarithm is negative, a negative value gets a relatively small weight, a positive value gets a relatively large weight, thus ensuring 
that the theil index is greater than zero.After calculating the theil index by the environmental characteristic variables, the decomposition inequality formula is adjusted to:

$$
\begin{gathered}
\text { Theil }(u)_{1}=\operatorname{Theil}(\bar{u}) \\
\operatorname{Theil}(u)_{2}=\sum_{m=1}^{M} W_{m} \operatorname{Theil}\left(u^{m}\right)
\end{gathered}
$$

The first item on the right side of formula (2) represents the inequality between groups, the second item is the inequality within the group. And $W_{m}$ represents the weight of the group, that is, the proportion of the $m$ group in the whole.

\section{Decomposition of consumption inequality coefficient}

The above decomposition of the household consumption inequality only considers the differences between the whole group and inside the group. However, due to the current China's urban and rural dual economic system,further decomposition of consumption inequality in response to urban-rural deviation has more practical significance.Drawing on method for determining the Gini coefficient decomposition and the contribution rate of each part, the overall inequality coefficient can be decomposed based on the group, in this way the contribution rate of urban, rural, urban and rural areas and remaining items etc. to the household consumption inequality coefficient can be obtained.Employing the estimated household consumption inequality coefficient above, to decompose the household consumption inequality coefficient, as follows:

$$
T=T_{u r}+\delta T_{u}+\beta T_{r}+T_{0}
$$

Among them, $T_{u r}$ indicates the coefficient of inequality in household consumption between urban and rural areas (or Gini coefficient), $T_{0}$ indicates the remaining items caused by the overlap of urban families and rural families consumption, and $\delta$ and $\beta$ are parameters respective. The expressions of $T_{u r} 、 \delta 、 \beta$ are:

$$
\begin{gathered}
T_{u r}=\frac{p_{u} p_{r}\left(c_{u}-c_{r}\right)}{c} \\
\delta=p_{u}{ }^{2}\left(\frac{c_{u}}{c}\right) \\
\beta=p_{r}{ }^{2}\left(\frac{c_{r}}{c}\right)
\end{gathered}
$$

Among them, $p_{u}$ 、represent the urban household share (the sample proportion) and the rural household share $p_{r}$, respectively; $c_{u} 、 c_{r} 、 c$ represent the annual average consumption 
expenditure levels of urban families, rural families, and urban and rural families, respectively. Existing Studies have shown that when the inequality coefficient is decomposed, if the overlap between the rural families with higher consumption and the urban families with lower consumption is ignored, the inequality coefficient would be underestimated[33,34,35].The remaining terms are defined as:

$$
T_{0}=2 p_{u} p_{r} \frac{\int\left[1-F_{u}(x)\right] F_{r}(x) d x}{c}
$$

As the urban and rural overall consumption inequality coefficient $T$, the urban household consumption inequality coefficient $T_{u}$ and the rural household consumption inequality coefficient $T_{r}$ have been calculated.The expressions of $T_{u r} 、 \delta$ and $\beta$ can be used to calculate the corresponding values. At last, according to the decomposition formula of the household consumption inequality coefficient, the remaining items of the household inequality coefficient can be further calculated, and the contribution rates of each project is calculated.

\section{Social welfare implications of consumption inequality coefficient}

According to Atkinson's[36] analysis of social welfare implications under income inequality, the meaning of social welfare under consumption inequality are more important.Since the inequality coefficient satisfies the "Pigou-Dalton Bundle Principle",that is, if wealthy people transfer income to low-income or poor people, but economic status of wealthy people does not change, the inequality coefficient of the whole society will be reduced[37,38,39].In this case, the entire social welfare and social inequality have formed a close correlation.In terms of consumption, the introduction of the "Pigou-Dalton Bundle Principle",that is, the shift of consumption from affluent people to low-income or poor people can also improve social inequality.

According to the Equal distribution of equal income (EDEI) theory[40,41], we can effectively link the inequality coefficient with the social welfare function. When using consumption as a measure of household inequality, it can be defined as Equal distribution of equal consumption (EDEC), denoted as $\xi$, means that when all families reach the consumption level $\xi$, the social welfare is the same as the social welfare under the established consumption distribution. Satisfy $W(\xi \bullet \overrightarrow{1})=W(C)$, where consumption distribution is $C=C\left(c_{1}, c_{2}, \ldots, c_{n}\right)$. Therefore, the inequality coefficient based on the social welfare function can be defined as:

$$
I=1-\xi / u_{c}
$$

In the above formula, $u_{c}$ represents the average household consumption. At the same time, suppose the social welfare function $W(X)$ is a linear homogeneous function, which is taken as:

$$
W(X)=\varphi\left(\sum_{i=1}^{n}(2 n-2 i+1) x_{i}\right)
$$


Where $\varphi($.$) is a monotonically increasing function, where the poor families in the welfare$ function are given greater weight,wealthy families are given a lower weight, and get the same value of consumption under the condition of average distribution in this social welfare function:

$$
\xi=\left(\sum_{i=1}^{n}(2 n-2 i+1) x_{i}\right) / n^{2}
$$

The inequality coefficient $T=1-\xi / u$, and thus the inequality coefficient is an inequality index with social welfare meaning, that is, there is a one-to-one correspondence between the Equal distribution of equal consumption (EDEC) and the social welfare function, that is:

$$
W(C) \equiv \xi=u_{c}(1-T)
$$

It is assumed that the inequality coefficient, the consumption mean value, and the social welfare at the time of $t_{1} 、 t_{2}$ are $T_{1} 、 u_{1} 、 W_{1}$ and $T_{2} 、 u_{2} 、 W_{2}$ respectively, so that factorization of social welfare changes during $t_{1}-t_{2}$ can be performed.Here, we consider the impacts of two aspects. On the one hand, we mainly focus on the impacts of economic growth on the changes of social welfare,which is defined as maintaining the level of household consumption inequality (consumption distribution), and only considering the variation of welfare caused by the changes of the average consumption;on the other hand,the impact of consumption distribution on social welfare changes is the main factor,defined as keeping the average household consumption constant, only considering changes of welfare due to the changes of consumption distribution.Thus, the change of social welfare during $t_{1}-t_{2}$ can be defined as:

$$
\Delta W=W_{G}+W_{D}=\left[u_{c 2}\left(1-T_{1}\right)-u_{c 1}\left(1-T_{2}\right)\right]+\left[u_{c 2}\left(1-T_{2}\right)-u_{c 2}\left(1-T_{1}\right)\right]
$$

That is:

$$
\Delta W=\Delta u\left(1-T_{1}\right)+u_{c 2}(-\Delta T)
$$

According to the definition above, it is also feasible to carry out another decomposition of social welfare changes:

$$
\Delta W=W_{G}+W_{D}=\left[u_{c 2}\left(1-T_{2}\right)-u_{c 1}\left(1-T_{2}\right)\right]+\left[u_{c 1}\left(1-T_{2}\right)-u_{c 1}\left(1-T_{1}\right)\right]
$$

That is:

$$
\Delta W=\Delta u\left(1-T_{2}\right)+u_{c 1}(-\Delta T)
$$

According to the two decomposition results, taking the arithmetic mean of the two,we can get: 


$$
\Delta W=W_{G}+W_{D}=\frac{1}{2} \Delta u\left(1-T_{1}+1-T_{2}\right)+\frac{1}{2}\left(u_{c 1}+u_{c 2}\right)(-\Delta T)
$$

Among them, the first item on the right side of the formula (16) is the growth effect $W_{G}$ of social welfare,the second item is distribution effect of social welfare $W_{D}$. And also we define $\gamma_{1}=W_{G} / \Delta W, \gamma_{2}=W_{D} / \Delta W$ and $\gamma_{3}=W_{D} / W_{G}$, which represent the proportion of growth effects to social welfare changes, the proportion of consumption distribution effects to social welfare changes, and the improvement of consumption distribution respectively.Among them, $\gamma_{3}>0$ indicates that the consumption distribution is improved, and the improvement of consumption distribution additionally increases $100 \gamma_{3} \%$ of social welfare that caused by economic growth;if $\gamma_{3}<0$, it means that the distribution of consumption deteriorates, and the deterioration of consumption distribution has offset $-100 \gamma_{3} \%$ of the increase of social welfare brought by the economic growth.

\section{Data}

The data was extracted from the China Health and Nutrition Survey (CHNS) database.The database covers data from of province in China with geographical characteristics, economic development levels, and differences in public resources and health indicators,a total of 10 surveys were conducted between 1989 and 2015,each survey interviewed approximately 4,400 families, including 19,000 individual samples and some community statistics. Ten surveys data were selected from 1989 to 2015 to conduct individual tracking studies.In data processing, year, individual ID, household ID and community ID are keywords,datas were merged in STATA15.0.Finally, valid sample data including 10 surveys of 12 provinces and municipalities including Beijing, Liaoning, Heilongjiang, Shanghai, Jiangsu, Shandong, Henan, Hunan, Hubei, Guangxi, Guizhou, and Chongqing were obtained. Furthermore, some missing values or invalid values were excluded.

\section{Results}

\section{Estimation of consumption inequality coefficient}

With the data of 1989 2015 CHNS survey,we first analyze the urban, rural and overall consumption inequality for comparison, at the same time, the urban and rural income inequality coefficients are analyzed,the results are shown in Table 1.

According to formula (2), the coefficient of inequality in household consumption can be estimated, at the same time, the household income inequality coefficient in the corresponding environmental context can be calculated.The results in Table 1 show that whether urban, rural, or as a whole,household income inequality coefficient is lower than the household consumption inequality coefficient.Among them, the urban-rural consumption inequality coefficient from 1989 to 2015 shows that consumption inequality coefficient of urban and rural households is higher than 0.45 ,after 2006, they are all above the level of 0.55 , and in the two years of 2011 and 2015 , the level exceeded the standard of 0.60,belonging to the high gap stage;rural household consumption inequality coefficient is higher than 0.40 . And after 2000, the rural household consumption inequality coefficient has been higher than 0.50 , much higher than the relatively reasonable interval of 0.40 . The urban household consumption inequality is also higher than the 
level of 0.35 ,however, the overall variation of consumption inequality is not obvious.

The decomposition of the consumption inequality coefficient and the income inequality coefficient shows that the calculation result is higher than the Gini coefficient published by the National Bureau of Statistics of China.Therefore, there are two questions require further clarification.First, what is the relationship among the consumption inequality, income inequality and the wealth inequality? The income inequality is a measure based on current income, which is reflecting the current income inequality; wealth inequality is more concerned of the accumulation of income,which is reflecting the accumulated income inequality in all phases of the household.Usually, the coefficient of wealth inequality is higher than the income inequality coefficient.For example, the CFPS survey report shows that China's wealth inequality coefficient is much higher than the income inequality coefficient.The measure of consumption inequality is subject to restrictions of income, wealth and credit and so forth (according to the definition of the consumption function in economic field, consumption is a function of income, wealth, etc.).According to the hypothesis of life cycle theory and the permanent income theory, consumption is the smoothing of life income.Therefore, the degree of discrete of consumption will be lower than the discrete of income,so that the consumption inequality coefficient will be lower than the income inequality coefficient,but the results of this study are on the contrary.The reason are:First,the definition of consumption in this study,which is different from previous researches.Here, consumption is defined as the overall consumption level of a family, it not only includes the consumption of household members involved in labor distribution, but also includes children and elderly who are purely consuming population not involved in labor distribution.Thus, the hypothesis of life cycle theory or permanent income theory are not valid here,both theories only consider the vertical distribution of individuals, but do not consider the horizontal distribution among different groups.Second, the household income statistics are different.Our statistics of household income not only consider the general labor income of the household, but also includes redistributed income, that means, it contains the government's transfer income to poor families and low-middle income. Such as direct social assistance funds, old-age subsidiaries etc,these parts of income will reduce the income inequality of the household to a certain extent,and policies such as high taxes on high-income families,will also reduce the gap between high-income families and low-income families.In turn, the coefficient of inequality of household consumption is higher than the coefficient of inequality of household income.Third, the coefficient of inequality in household consumption is higher than the coefficient of inequality in household income, is also caused by the difference in household wealth.Short-term social assistance or insurance policies cannot fundamentally solve the long-term wealth accumulation differences between families.Consumption is an external behavior of accumulation of wealth, and wealth directly affects the level of consumption.Poverties or low-income families pay more attention to the accumulation of wealth.They focus on consumption rigidity and reducing ex consumption, which leads to the continuous expansion of inequality of household consumption levels.

Table 1 Consumption inequality coefficient and income inequality coefficient 


\begin{tabular}{ccccccc}
\hline Year & \multicolumn{2}{c}{ consumption inequality coefficient } & \multicolumn{3}{c}{ income inequality coefficient } \\
\cline { 2 - 6 } & $T_{r}$ & $T_{u}$ & $T$ & $I_{r}$ & $I_{u}$ & $I$ \\
\hline 1989 & 0.4703 & 0.5438 & 0.4908 & 0.4029 & 0.3764 & 0.4080 \\
1991 & 0.4469 & 0.5551 & 0.4812 & 0.3699 & 0.3739 & 0.3843 \\
1993 & 0.4957 & 0.4733 & 0.5054 & 0.3932 & 0.4056 & 0.4043 \\
1997 & 0.4797 & 0.5154 & 0.4976 & 0.3859 & 0.3896 & 0.3929 \\
2000 & 0.5311 & 0.4068 & 0.5235 & 0.4012 & 0.3860 & 0.4073 \\
2004 & 0.5027 & 0.3660 & 0.4952 & 0.4106 & 0.3762 & 0.4143 \\
2006 & 0.5645 & 0.4200 & 0.5547 & 0.4302 & 0.3943 & 0.4307 \\
2009 & 0.5665 & 0.5684 & 0.5762 & 0.4300 & 0.3638 & 0.4301 \\
2011 & 0.5542 & 0.6520 & 0.6035 & 0.3952 & 0.3539 & 0.3951 \\
\hline & 0.6307 & 0.5669 & 0.6319 & 0.4462 & 0.3712 & 0.4400 \\
\hline
\end{tabular}

Note: Here, the income inequality coefficient measurement method is the same as the consumption inequality coefficient measurement method,decompose household income inequality into opportunity inequality and effort inequality, thereby obtaining the total income inequality coefficient of the household.

\section{Decomposition of consumption inequality coefficient}

Urban household consumption inequality coefficient, rural household consumption inequality coefficient and overall household inequality coefficient have been calculated.According to formula (4), $T_{u r}$ can be subsequently calculated, also, $\delta$ and $\beta$ can be calculated by using formulas (5) and (6).According to formula (3),we can consequently calculate $T_{0}$. Table2 presents the decomposition results of the household consumption inequality coefficient and the contribution rate of different parts to the consumption inequality coefficient.

Table 2 shows that overall consumption inequality is caused by consumption inequality of the rural areas.Second, from 1989 to 2015, the consumption inequality coefficient of different parts has undergone major changes.Among them, the contribution rate of household consumption inequality coefficient between urban and rural areas increased from $0.29 \%$ to $3.54 \%$ (average annual value is $4.37 \%$ ); the contribution rate of household consumption inequality coefficient in urban areas decreased from $3.34 \%$ to $1.47 \%$ (average annual value of $2.18 \%$ ); the contribution rate of household consumption inequality coefficient in rural areas increased from $65.38 \%$ to $85.58 \%$ (average annual value is $73.49 \%$ ); the contribution rate of household consumption inequality coefficient of remaining items reduced from $30.99 \%$ to $9.40 \%$ (average annual value was $19.97 \%$ ).

The rural areas consumption inequality coefficient and the remaining consumption inequality coefficient have the highest contribution rate,which suggests that the current imbalance between urban and rural consumption in China is shrinking,but the consumption inequality caused by the 
changes in household structure in rural areas is increasing,and the consumption overlap between urban low-income groups and rural high-income groups is increasing.From the overall trend,the contribution rate of urban between rural, urban areas and remaining items consumption inequality are decreasing,which indicates that China's urban-rural dual economic system has been alleviated, and the urban-rural consumption gap is narrowing.At the same time, the consumption gap of urban areas is narrowing, and the overlap of urban low-income groups and rural high-income groups is also shrinking year by year.However, the contribution rate of consumption inequality coefficient in rural areas is increasing gradually,indicating the changes of household economic structure in rural areas, and the gap is gradually widening.This kind of consumption deviation and convergence is related to the income level and consumption behavior of urban and rural families:in urban areas, urban residents have higher income levels,and from 1989 to 2015, its internal income inequality coefficient is also decreasing.Coupled with rapid economic development, the consumption convergence of urban residents is increasing, thus a lower contribution rate of the consumption inequality coefficient appeared;in the rural areas, after China's reform and opening up,differences in regional economic development levels have propelled more and more rural populations to migrate to urban or developed areas for employment,however, due to restrictions of "hukou"(household registration), migrated population still belongs to rural "hukou",while their actual consumption structure is similar to urban residents,that makes consumption overlap is on the rise, which leads to the differentiation of household consumption within the rural areas.

Table 2 Decomposition results of consumption inequality coefficient and contribution rate of each part

\begin{tabular}{|c|c|c|c|c|c|c|c|c|c|}
\hline \multirow[b]{2}{*}{ Year } & \multirow{2}{*}{$\begin{array}{c}\text { Total } \\
T\end{array}$} & \multicolumn{2}{|c|}{ Urban and rural } & \multicolumn{2}{|c|}{ Urban areas } & \multicolumn{2}{|c|}{ Rural areas } & \multicolumn{2}{|c|}{ Remaining items } \\
\hline & & $T_{u r}$ & $\begin{array}{c}\text { Contribu } \\
\text { tion rate } \\
(\%)\end{array}$ & $T_{u}$ & $\begin{array}{c}\text { Contrib } \\
\text { ution } \\
\text { rate } \\
(\%)\end{array}$ & $T_{r}$ & $\begin{array}{c}\text { Contrib } \\
\text { ution } \\
\text { rate }(\%)\end{array}$ & $T_{\mathrm{o}}$ & $\begin{array}{c}\text { Contribu } \\
\text { tion rate } \\
(\%)\end{array}$ \\
\hline 1989 & 0.4908 & 0.0014 & 0.29 & 0.0164 & 3.34 & 0.3209 & 65.38 & 0.1521 & 30.99 \\
\hline 1991 & 0.4812 & 0.0464 & 9.64 & 0.0175 & 3.64 & 0.3010 & 62.55 & 0.1163 & 24.17 \\
\hline 1993 & 0.5054 & 0.0343 & 6.79 & 0.0118 & 2.33 & 0.3504 & 69.33 & 0.1089 & 21.55 \\
\hline 1997 & 0.4976 & 0.0279 & 5.61 & 0.0142 & 2.85 & 0.3331 & 66.94 & 0.1224 & 24.60 \\
\hline 2000 & 0.5235 & 0.0197 & 3.76 & 0.0062 & 1.18 & 0.4073 & 77.80 & 0.0903 & 17.25 \\
\hline 2004 & 0.4952 & 0.0080 & 1.62 & 0.0053 & 1.07 & 0.3893 & 78.61 & 0.0926 & 18.70 \\
\hline 2006 & 0.5547 & 0.0118 & 2.13 & 0.0073 & 1.32 & 0.4992 & 89.99 & 0.0364 & 6.56 \\
\hline 2009 & 0.5762 & 0.0006 & 0.10 & 0.0085 & 1.48 & 0.4366 & 75.77 & 0.1305 & 22.65 \\
\hline 2011 & 0.6035 & 0.0615 & 10.19 & 0.0185 & 3.07 & 0.3800 & 62.97 & 0.1435 & 23.78 \\
\hline 2015 & 0.6319 & 0.0224 & 3.54 & 0.0093 & 1.47 & 0.5408 & 85.58 & 0.0594 & 9.40 \\
\hline
\end{tabular}


Based on the consumption inequality coefficients.From formula (9) and Table 1, we can calculate household social welfare during 1989 - 2015.Further, social welfare changes can be decomposed by formula (16). The changes of urban, rural and overall social welfare are shown in Tables 3, 4 and 5, respectively.

Table 3 shows that urban household social welfare increased from 774.21 in 1989 to 1232.95 in 2015,with a net increase of 458.74.The decomposition of social welfare illustrates that the growth effect of social welfare is 1229.91 , while the distribution effects of social welfare is -771.17 ,which is, $\gamma_{3}$, the deterioration in consumption distribution offsets $62.70 \%$ of increment in social welfare brought by the economic growth.Therefore, from 1989 to 2015, economic growth and consumption distribution together led to changes of urban social welfare,while economic growth is the dominant force of overall increment of urban social welfare.In 2000 and 2015, due to the economic downturn and the deterioration of consumption distribution, social welfare of urban families was reduced.

According to Table 3 rural household social welfare increased from 766.72 in 1989 to 1998.54 in 2015, with a net increase of 1231.82.The decomposition of social welfare shows that the growth of social welfare is 1897.11 , and the social welfare growth effect reaches $154.01 \%$,yet the distribution effect of social welfare is -665.29 , and the proportion of social welfare distribution effect is $-54.01 \%$. The improvement in consumption distribution has increased extra increment of welfare brought by the economic growth by 35.07\%.Therefore, from 1989 to 2015, economic growth and consumption distribution also together caused changes of rural social welfare, with economic growth as the dominant force causing overall increment of rural social welfare.In the year of 1991, 2000, 2011 and 2015, the economic downturn and the deterioration of consumption distribution together led to an overall decline in rural social welfare.

The overall social welfare increased from 768.05 in 1989 to 1719.62 in 2015, with a net increase of 951.57, as shown in Table 3.The decomposition of social welfare shows that the growth of social welfare is 1606.17 , where growth effect reaches $168.79 \%$.The distribution of social welfare is -654.60 , where the proportion of social welfare distribution effect is $-68.79 \%$. The deterioration in consumption distribution offsets the $-40.76 \%$ increase in social welfare caused by economic growth.Therefore, economic growth and consumption distribution caused changes in urban and rural social welfare, but economic growth was the dominant force causing the overall increment of social welfare.In 2000 and 2015, the economic downturn and deterioration of consumption distribution together led to a decline in overall social welfare.

Table 3 Changes in Urban and Rural Social Welfare and Their Decomposition from 1989 to 2015

\begin{tabular}{ccccccccccc}
\hline \multicolumn{4}{c}{ Urban and Rural Social Welfare } & \multicolumn{3}{c}{ Rural Social Welfare } & \multicolumn{3}{c}{ Urban Social Welfare } \\
\hline Year & $\gamma_{1}(\%)$ & $\gamma_{2}(\%)$ & $\gamma_{3}(\%)$ & $\gamma_{1}(\%)$ & $\gamma_{2}(\%)$ & $\gamma_{3}(\%)$ & $\gamma_{1}(\%)$ & $\gamma_{2}(\%)$ & $\gamma_{3}(\%)$ \\
\hline 1991 & 93.09 & 6.91 & 7.42 & 152.17 & -52.17 & -34.28 & 93.09 & 6.91 & 7.42 \\
1993 & 125.58 & -25.58 & -20.37 & 119.46 & -19.46 & -16.29 & 125.58 & -25.58 & -20.37
\end{tabular}




\begin{tabular}{|c|c|c|c|c|c|c|c|c|c|}
\hline 1997 & 96.99 & 3.01 & 3.10 & 97.27 & 2.73 & 2.81 & 96.99 & 3.01 & 3.10 \\
\hline 2000 & 89.93 & 10.07 & 11.20 & 60.54 & 39.46 & 65.18 & 89.93 & 10.07 & 11.20 \\
\hline 2004 & 84.54 & 15.46 & 18.29 & 78.29 & 21.71 & 27.73 & 84.54 & 15.46 & 18.29 \\
\hline 2006 & 149.71 & -49.71 & -33.20 & 291.99 & -191.99 & -65.75 & 149.71 & -49.71 & -33.20 \\
\hline 2009 & 133.54 & -33.54 & -25.11 & 118.83 & -18.83 & -15.84 & 133.54 & -33.54 & -25.11 \\
\hline 2011 & 112.41 & -12.41 & -11.04 & 9.96 & 90.04 & 904.19 & 112.41 & -12.41 & -11.04 \\
\hline 2015 & 93.79 & 6.21 & 6.62 & 68.17 & 31.83 & 46.70 & 93.79 & 6.21 & 6.62 \\
\hline 1989 20 & 268.11 & -168.11 & -62.70 & 154.01 & -54.01 & 35.07 & 268.11 & -168.11 & -62.70 \\
\hline 15 & & & & & & & & & \\
\hline
\end{tabular}

\section{Non-medical consumption inequality coefficient and family social welfare}

In further analysis, we divided household consumption into medical consumption and non-medical consumption, and estimated changes in social welfare caused by inequality of non-medical consumption in households. There is no measure of inequality in family medical consumption here, because the incidence of disease risk varies in different types of families, and the high coverage of social medical insurance can alleviate the inequality of medical consumption of ordinary families to a certain extent.The evolution of social welfare caused by inequality of non-medical consumption of households is shown in Table 4.The results show that from 1989 to 2015, the overall welfare increase under urban and rural non-medical consumption was 64.04, of which 188.92 in urban areas and 137.65 in rural areas.The breakdown of social welfare shows that under non-medical consumption inequality, the growth effect of social welfare is $379.40 \%$, and the distribution effect is $-279.40 \%$. The worsening consumption distribution offsets the $73.64 \%$ of the increase in social welfare caused by economic growth.The differences in the welfare distribution characteristics of urban and rural overall consumption under the same circumstances are small, indicating that non-medical consumption is the main cause of urban and rural overall consumption inequality. This conclusion will be further verified later.The deterioration in the distribution of non-medical consumption in urban and rural households offset $48.42 \%$ and $69.39 \%$ of the increase in social welfare caused by economic growth, which are lower and higher than the deterioration in consumption distribution under the total consumption sample, indicating that the difference in urban and rural areas is different. Under the region, there are differences in the impact of medical security on household non-medical consumption, thus showing inconsistencies in the evolution of social welfare.

Table 4 Changes in overall social welfare and sub-regions based on non-medical consumption from 1989 to 2015

$\begin{array}{ccc}\text { Urban and rural general } & \text { Urban non-medical } & \text { Rural non-medical } \\ \text { welfare under non-medical } & \text { consumption social welfare } & \text { consumption social welfare }\end{array}$




\begin{tabular}{|c|c|c|c|c|c|c|c|c|c|}
\hline & & onsumptio & & & & & & & \\
\hline Year & $\gamma_{1}(\%)$ & $\gamma_{2}(\%)$ & $\gamma_{3}(\%)$ & $\gamma_{1}(\%)$ & $\gamma_{2}(\%)$ & $\gamma_{3}(\%)$ & $\gamma_{1}(\%)$ & $\gamma_{2}(\%)$ & $\gamma_{3}(\%)$ \\
\hline 1991 & 119.10 & -19.10 & -16.03 & -25.75 & 125.75 & -488.40 & 9.85 & 90.15 & 915.32 \\
\hline 1993 & 209.06 & -109.06 & -52.17 & 37.24 & 62.76 & 168.56 & 1338.64 & -1238.6 & -92.53 \\
\hline 1997 & 69.32 & 30.68 & 44.26 & 60.32 & 39.68 & 65.77 & 76.26 & 23.74 & 31.13 \\
\hline 2000 & 13.40 & 86.60 & 646.02 & 979.11 & -879.11 & -89.79 & 11.61 & 88.39 & 761.15 \\
\hline 2004 & 48.87 & 51.13 & 104.65 & 88.79 & 11.21 & 12.62 & 48.46 & 51.54 & 106.36 \\
\hline 2006 & -149.58 & 249.58 & -166.85 & 131.66 & -31.66 & -24.05 & -140.30 & 240.30 & -171.28 \\
\hline 2009 & 106.83 & -6.83 & -6.40 & -1.43 & 101.43 & -7071.9 & 79.12 & 20.88 & 26.39 \\
\hline 2011 & 67.76 & 32.24 & 47.58 & -31.34 & 131.34 & -419.08 & 80.70 & 19.30 & 23.92 \\
\hline 2015 & 18.61 & 81.39 & 437.35 & -81.56 & 181.56 & -222.61 & 127.49 & 87.25 & 684.40 \\
\hline $\begin{array}{c}1991 \sim 2 \\
015\end{array}$ & 379.40 & -279.40 & -73.64 & 193.89 & -93.89 & -48.42 & 326.73 & -226.73 & -69.39 \\
\hline
\end{tabular}

\section{Discussion}

\section{Variable selection and descriptive statistics}

In order to test the accuracy of the previous estimation results, we conduct an extended test on the existing conclusions to ensure the reliability of the research conclusions[].First, we assess income inequality and consumption inequality by grouping families.Secondly, in terms of data selection, we selected income inequality, illness and participation in medical insurance as the core explanatory variables. We control the individual age, age range, work, education, and family size of family members. At the same time, the dummy variables of year, province and urban-rural are also controlled in different models. Descriptive statistics of core variables are shown in Table 5.

Table5 Descriptive statistics of core variables

\begin{tabular}{cccc}
\hline variable & Variable definitions & mean & S.d. \\
\hline Income inequality & Theil Index Measurement of Income Inequality by Family Groups & 0.40 & 0.29 \\
Consumption inequality & Theil Index Measurement of Consumer Inequality in Family Groups & 0.39 & 0.29 \\
Inequality in medical & Theil Index Measurement of Medical Consumption Inequality by & 0.45 & 0.40 \\
consumption & Family Groups &
\end{tabular}


Non-medical

consumption inequality

Unequal income growth

If ill

medical insurance

job

age

Under 18 years of age

$18 \sim 59$ years old

Over 60 years old

education level

Family size

Urban and rural
Theil Index Measurement of Non-medical Consumption Inequality

by Family Groups

Theil Index Measurement of Income Growth Inequality by Family

Groups

$0.37 \quad 0.27$

$0.11 \quad 0.32$

$0.50 \quad 0.50$

Participating in work $=1$, not participating in work $=0$

$0.66 \quad 0.47$

$37.06 \quad 21.22$

The age of the respondent in the survey year, in years

$0.23 \quad 0.42$

$0.60 \quad 0.49$

Ages 18 to 59 are defined as 1 , others are 0

$0.17 \quad 0.37$

Age 60 and above is defined as 1 , others are 0

Elementary school and below=1,junior high school=2, high

school $=3$, vocational $\operatorname{school}=4$, college or university $=5$, master's

$1.62 \quad 1.38$

degree and above $=6$

Family population

4.16

1.61

Urban $=1$, rural $=0$

0.33

0.47

\section{Empirical}

\section{Causes of household consumption inequality}

The family disease and medical insurance factors are introduced into the model for testing. The test results are shown in Table 6.The mixed OLS test results of model (1) show that income inequality is the core influencing factor of household consumption inequality.And income inequality directly leads to increased consumption inequality, and participation in medical insurance and illness significantly reduces household inequality.The significant negative effect of illness here may be partly due to the influence of different parts of the consumption composition, and disease expenditure will reduce household non-medical consumption, which will be further verified later.Models (2) are tests based on fixed effects. The results show that income inequality is still a significant positive influencing factor, while participation in medical insurance is no longer significant, and the level of disease variables is significantly reduced. 


\begin{tabular}{|c|c|c|}
\hline & Mixed OLS test & Panel FE effect test \\
\hline & (1)By age group & (2)By age group \\
\hline \multirow{3}{*}{ Income inequality } & $0.2340^{* * *}$ & $0.2140^{* * *}$ \\
\hline & & \\
\hline & $(0.00521)$ & $(0.0055)$ \\
\hline \multirow{3}{*}{ medical insurance $=1$} & $-0.0126^{* * *}$ & 0.0025 \\
\hline & & \\
\hline & $(0.0040)$ & $(0.0041)$ \\
\hline \multirow[t]{2}{*}{ If ill $=1$} & $-0.0134^{* * *}$ & $-0.0090^{*}$ \\
\hline & $(0.0047)$ & $(0.0047)$ \\
\hline Year & Yes & Yes \\
\hline Urban and rural & Yes & Yes \\
\hline \multirow[t]{2}{*}{ Constant term } & $1.001^{*}$ & $1.171^{* *}$ \\
\hline & $(0.512)$ & $(0.531)$ \\
\hline Sample & 32617 & 32617 \\
\hline
\end{tabular}

Note: Standard deviations in parentheses, ${ }^{*} p<0.1,{ }^{* *} p<0.05,{ }^{* * *} p<0.01$. Control variables such as age,education level, work, illness, family size, and other control variables in the table are not listed. The Hausman test results for panel RE and FE show that prob $>$ chi2 $=0.0072$, which significantly rejects the null hypothesis of random effects. FE models should be used.

\section{Causes of Consumption Inequality in Urban and Rural Households}

Based on the verification of the causes of aggregate consumption inequality, we continue to examine the consumption inequality in the urban-rural classification area.As shown in Table 7, Model (1) and (2) are the test results by age and different age groups. The results show that income inequality is still a significant influencing factor of urban and rural consumption inequality. Participation in medical insurance has a significant negative effect on inequality of consumption in urban households, but the disease is not significant.Participating in medical insurance has a significant positive effect on inequality of consumption in rural households, and it has a significant negative effect on illness. That is, medical security has increased the inequality of consumption in rural households, this result is verified in models (3) and (4).In the model (3) with medical consumption as the explanatory variable, illness significantly raises inequality in family medical consumption. And medical insurance has not significantly reduced family medical consumption, that is, adverse selection and moral hazard in medical insurance in reality.The test results of non-medical consumption as the explanatory variable model (4) show that illness reduces household inequality of non-medical consumption, and medical insurance does not show a significant positive effect. 
Due to the endogenous effect of income inequality on household consumption inequality, Davidson-MacKinnon test results show that the $\mathrm{P}$ value is 0 , which means that there is an endogenous problem. We use inequality of household income growth as an instrumental variable for endogenous treatment, and the results are shown in model (5).The results of the instrumental variable method show that income inequality still has a significant positive effect on household consumption inequality.

Table 7 Panel fixed effect test and IV treatment of inequality in consumption between urban and rural households

\begin{tabular}{|c|c|c|c|c|c|}
\hline & \multicolumn{2}{|c|}{ Consumption inequality by Urban-rural } & \multicolumn{2}{|c|}{$\begin{array}{c}\text { Comparison by Medical } \\
\text { Consumption }\end{array}$} & \multirow{2}{*}{$\begin{array}{c}\text { IV treatment } \\
\text { Panel IV test } \\
\text { (5) }\end{array}$} \\
\hline & $\begin{array}{c}\text { Urban } \\
\text { consumption } \\
\text { inequality FE (1) }\end{array}$ & $\begin{array}{c}\text { Rural } \\
\text { consumption } \\
\text { inequality FE (2) }\end{array}$ & $\begin{array}{l}\text { Medical } \\
\text { consumptio } \\
\text { n FE (3) }\end{array}$ & $\begin{array}{l}\text { Non-medical } \\
\text { consumption } \\
\text { FE (4) }\end{array}$ & \\
\hline \multirow{2}{*}{ Income inequality } & $0.2030^{* * *}$ & $0.2140^{* * *}$ & $0.1800^{* * *}$ & $0.2150^{* * *}$ & $0.3770^{* * *}$ \\
\hline & $(0.0140)$ & $(0.0060)$ & $(0.0281)$ & $(0.0056)$ & $(0.0055)$ \\
\hline \multirow{2}{*}{ if ill $=1$} & 0.0077 & $-0.0109^{* *}$ & $0.0431^{* *}$ & $-0.0113^{* *}$ & $-0.0127^{* * *}$ \\
\hline & $(0.0113)$ & $(0.0052)$ & $(0.0183)$ & $(0.0055)$ & $(0.0048)$ \\
\hline medical & $-0.0248^{* * *}$ & $0.0095^{* *}$ & -0.0213 & 0.0036 & $-0.0102^{* *}$ \\
\hline insurance $=1$ & $(0.0095)$ & $(0.0046)$ & $(0.0194)$ & $(0.0042)$ & $(0.0047)$ \\
\hline Year / Province & YES & YES & YES & YES & YES \\
\hline Urban- rural & YES & YES & YES & YES & YES \\
\hline \multirow[t]{2}{*}{ Constant term } & $-2.391^{*}$ & $2.000^{* * *}$ & -0.836 & $0.973^{*}$ & $0.1100^{* * *}$ \\
\hline & $(1.273)$ & $(0.588)$ & $(2.725)$ & $(0.548)$ & $(0.0129)$ \\
\hline Davidson-MacKinn & & & & & $\mathrm{F}(1,32597)$ \\
\hline on test & & & & & $\mathrm{P}=0.00$ \\
\hline First stage $F$ value & & & & & 106.38 \\
\hline Sample & 4528 & 28089 & 3246 & 29371 & 32616 \\
\hline \multicolumn{6}{|c|}{$\begin{array}{l}\text { Note: Standard deviations in parentheses, }{ }^{*} p<0.1,{ }^{* *} p<0.05,{ }^{* * *} p<0.01 \text {. Control variables such as age, } \\
\text { education level, work, illness, family size, and other control variables in the table are not listed. Hausman test } \\
\text { results for panel RE and FE show that prob }>\text { chi } 2=0.0000 \text {, which significantly rejects the null hypothesis of } \\
\text { random effects. FE model should be used. }\end{array}$} \\
\hline
\end{tabular}




\section{Research limitations}

On the one hand, our research is based on a family medical perspective, and the time span is from 1989 to 2015. However, in actual surveys, surveys on household consumption are rarely able to carry out a divestiture survey directly. Surveys on total household consumption generally include medical out-of-pocket expenses, which can cause limited and biased estimates. On the other hand, due to limited existing survey data, it is not possible to compare more detailed consumption categories, thus providing reliable support for better research conclusions.

\section{Conclusions}

Based on the 10 microscopic survey data of CHNS from 1989 to 2015, this study measures and decomposes the household consumption inequality coefficient,and analyses social welfare based on the coefficient of inequality of household consumption. The results of this study are:First, regardless of either urban or rural areas, or as a whole, the household income inequality coefficient is lower than the household consumption inequality coefficient.Among them, the consumption inequality coefficient of urban and rural families is higher than 0.45 ; the rural household consumption inequality coefficient is higher than 0.40 ; and the urban household consumption inequality coefficient is also higher than the level of 0.35 , but the variation of overall consumption inequality coefficient is not significant.Second, the overall consumption inequality is caused by the inequality inside rural areas, and then the contribution rate of the remaining items.The contribution rate of household consumption inequality coefficient of rural areas increased from $65.38 \%$ to $85.58 \%$ (average value is $73.49 \%$ ); the contribution rate of remaining consumption inequality increased from $30.99 \%$ to $9.40 \%$ (average value was $19.97 \%$ ). Third, the expansion test results show that income inequality is a significant positive factor that causes household consumption inequality, and the test results of instrumental variables are robust.However, in other factors, participation in medical insurance and illness also have a significant impact on household inequality.And participating in medical insurance has significantly reduced inequality in urban consumption and significantly increased inequality in rural consumption.Fourth, according to the comparison of medical consumption, illness increases household inequality in medical consumption, while reducing household inequality in non-medical consumption.

The main conclusions are:First,policies issued by government must balance efficiency and fairness, and the government's policy orientation should be weighted between the two.According to the idea of marginalism, the trade-off between efficiency and fairness should reach a state,that the growth of social welfare increased by efficiency, and the deterioration of consumption distribution on the loss of social welfare, have to satisfy the principle of equivalence.Or the loss of social welfare due to reduction of efficiency and the social welfare improvement due to the improvement of consumption distribution should satisfy the principle of equivalence.

Second,the consumption has a richer meaning than income, and consumption inequality has a richer implication than income inequality.In the context of reducing inequality, consumption inequality has two dimensions:one is the inequality of consequence, and the other is the inequality in the process .In terms of inequality of results, consumption is the result of consumption 
decisions under conditions of wealth, income, and credit.In terms of inequality in the process, consumption is the process of acquiring social resources, the process of human capital accumulation, and the process of formation of income capacity.Therefore, to reduce consumption inequality, it is necessary to reduce the consumption inequality of results, and also to reduce the consumption inequality in the process. To narrow the consumption inequalities of results, the most important thing is to improve the basis of consumption decisions of low-income groups, that are wealth and income. Involving the rural residents and low-income groups in the benefits of economic opening and marketization process;raising the minimum wage standard and establishing a wage adjustment system;increasing efforts of precise poverty alleviation, improving systems of precise poverty alleviation, and optimizing the measures of precise poverty alleviation.To reduce the consumption inequality in the process, the most important thing is to reform the economic and social system to promote equality of opportunities. Inequality in consumption in the process would transform to the consumption inequality of consequence through a series of paths .Reduce consumption inequality in the process is an important way to promote equal opportunities and promote social equity,and the fairness of social opportunities affects social mobility.

\section{Reference}

[1] Blundell R, \& Etheridge B.Consumption, income and earnings inequality in britain. Review of Economic Dynamics.2010;13(1), 76-102.

[2] Benjamin D, \& Brandt L.Markets and inequality in rural china: parallels with the past. American Economic Review.1999;89(2), 292-295.

[3] Morduch J, \& Sicular T. Rethinking inequality decomposition, with evidence from rural china. Economic Journal.2010;112(476), 93-106.

[4] Khan A R, \& Riskin C.Income and inequality in china: composition, distribution and growth of household income, 1988 to 1995 . The China quarterly.1998;154(6), 221-253.

[5] Kanbur R, \& Zhang X.Which regional inequality? the evolution of rural-urban and inland-coastal inequality in china from 1983 to 1995. Journal of Comparative Economics.1999;27(4), 529-567.

[6] Khan A R , Griffin K, \& Riskin C. Income Distribution in Urban China during the Period of Economic Reform and Globalization.American Economic Review.1999;89 (5): 296-300.

[7] Meng X.Economic restructuring and income inequality in urban china. Review of Income and Wealth.2004;50(3), 357-379.

[8] Knight J,\&Li S.Three poverties in urban china. Review of Development Economics.2006;10(3), 367-387.

[9] Brzozowski M, Gervais M, Klein P, \& Suzuki M.Consumption, income, and wealth inequality in canada. Review of Economic Dynamics.2010;13(1), 52-75.

[10] Norris S, \& Pendakur K.Consumption inequality in canada, 1997 to 2009. Canadian Journal of Economics/Revue canadienne dl"économique.2015;48(2), 773-792.

[11] Attanasio O, Berloffa G, Blundell R, \& Preston I.From earnings inequality to consumption inequality. Economic Journal.2010;112(3), 52-59. 
[12] Cai H B,Chen Y Y,Zhou L A.Income and consumption inequality in urban china: 19922003. Economic Development and Cultural Change.2010;58(3), 385-413.

[13] Fisher J D, Johnson D S , \& Smeeding T M. Measuring the trends in inequality of individuals and families: income and consumption. American Economic Review.2013;103(3), 184-188.

[14] Heshmati A, \& Rudolf R.Income versus consumption inequality in korea: evaluating stochastic dominance rankings by various household attributes. Asian Economic Journal.2014;28(4), 413-436.

[15] Jappelli $T$, \& Pistaferri L.Does consumption inequality track income inequality in italy?. Review of Economic Dynamics.2010;13(1), 133-153.DOI: 10.1016/j.red.2009.11.001

[16] Fukushige M.On the determinants of households/" consumption inequality: an empirical analysis for japanese workers।" households. Applied Economics Letters.1996;3(8), 541-544.

[17] F.Crossley T,and Pendakur K.Consumption Inequality.Department of Economics working paper series, McMaster University,2002.

[18] Attanasio O, \& Pistaferri L.Consumption inequality over the last half century: some evidence using the new psid consumption measure.American Economic Review.2014;104(5), 122-126.

[19] Mark Aguiar, M B.Has consumption inequality mirrored income inequality. American Economic Review.2015;105(9), 2725-2756.

[20] Abe N, \& Yamada T.Nonlinear income variance profiles and consumption inequality over the life cycle. Journal of the Japanese \& International Economies.2009;23(3), 344-366.

[21] Lise J, Sudo N, Suzuki M, Yamada K, \& Yamada T. Wage, income and consumption inequality in japan, 1981-2008: from boom to lost decades. Review of Economic Dynamics.2014;17(4), 582-612.

[22] Kaplanoglou G, \& Rapanos V T.Evolutions in consumption inequality and poverty in greece: the impact of the crisis and austerity policies. Review of Income and Wealth.2016;64(1):105-126.

[23] De Nardi M, \& Fella G.Saving and wealth inequality. Review of Economic Dynamics.2017;26:280-300.

[24] Cutler D M , \& Katz L F.Rising inequality? changes in the distribution of income and consumption in the 1980's. American Economic Review.1992;82 (May): 546-51.

[25] Johnson D , \& Shipp S.Trends in inequality using consumption - expenditures: the u.s. from 1960 to 1993. Review of Income and Wealth.1997;43(2),133-152.

[26] Blundell R , \& Preston I.Consumption inequality and income uncertainty. The Quarterly Journal of Economics.1998;113(2), 603-640.

[27] Pendakur K.Changes in canadian household income and household consumption inequality between 1978 and 1992. Review of Income and Wealth.1998;44(2),259-283.

[28] Roemer J E.Equality of Opportunity: A Progress Report. Social Choice \& Welfare.2002;19 (2) : 455-471.

[29] Roemer J E.On several approaches to equality of opportunity. Economics and Philosophy.2012;28(02), 165-200.

[30] Ferreira F H G , \& Jérémie G.The measurement of inequality of opportunity: theory and an application to latin america. Review of Income and Wealth.2011;57 (4) : 622-657.

[31] Bourguignon F.Decomposable income inequality measures. Econometrica.1979;47(4), 901-920.

[32] Shorrocks A F.The class of additively decomposable inequality measures. 
Econometrica.1980;48(3), 613-625.

[33] Kai-Yuen T.Trends and inequalities of rural welfare in china: evidence from rural households in guangdong and sichuan. Journal of Comparative Economics. 1998;26(4), 783-804.

[34] Lise J , \& Seitz S. Consumption inequality and intra-household allocations. The Review of Economic Studies.2011;78(1), 328-355.

[35] Kapeller J , \& Schütz B. Conspicuous consumption, inequality and debt: the nature of consumption-driven profit-led regimes. Metroeconomica.2015;66(1), 51-70.

[36] Atkinson A B.On the measurement of inequality. Journal of Economic Theory.1970;2(3), 244-263.

[37] Pigou A C.Wealth and welfare. Macmillan and Company,limited,1912.

[38] Dalton H.The measurement of the inequality of incomes. The Economic Journal.1920;30(119), 348-361.

[39] Ohtake F , \& Saito M.Population aging and consumption inequality in japan. Review of Income and Wealth.1998;44(3), 361-381.

[40] Barreti G F , Crossley T F , \& Worswick C. Demographic trends and consumption inequality in australia between 1975 and 1993. Review of Income and Wealth,.2000;46(4):437-456.

[41] Meyer B D , \& Sullivan J X. Consumption and income inequality and the great recession. American Economic Review.2013;103(3), 178-183. 